\title{
ELASTIC POLYPROPYLENE SUTURE IN CATARACT SURGERY: LONG-TERM FOLLOW-UP
}

\author{
A. M. O'DRISCOLL, M. M. QURAISHY and N. C. ANDREW \\ Canterbury
}

\begin{abstract}
SUMMARY
The final part of a prospective, controlled study of elastic polypropylene suture for cataract surgery was undertaken. The aim was to determine the change in induced astigmatism at $\mathbf{3 0}$ months after extracapsular cataract surgery and to assess the long-term safety of the suture material. Thirty-two of $\mathbf{4 4}$ patients were reexamined for changes in astigmatism. The results of all examinations were subjected to vector analysis. Both the elastic polypropylene group and the nylon control group continued to show an increase in the against-therule component of astigmatism. There was no statistical difference $(p<0.5)$ between the two groups at 30 months post-operatively, though the shift was greater in the polypropylene group. Wound security was similar for both groups but the polypropylene group had a higher incidence of giant papillary conjunctivitis $(24 \%)$ due to exposed suture ends. The nylon suture was hydrolysed in $89 \%$ of that group and all patients were asymptomatic.
\end{abstract}

We undertook the long-term follow up of patients who had been recruited (from February 1992) to a prospective, controlled study of a new elastic polypropylene suture (Opthamend 9/0: Deknatel, Inc.) designed to reduce astigmatism in cataract surgery. ${ }^{1}$ This make of polypropylene suture is particularly elastic due to a modified manufacturing process. The aim of this part of the study was to analyse the trend of surgically induced astigmatism and to establish whether elastic polypropylene suture is safe for routine extracapsular cataract surgery in the long term.

\section{PATIENTS AND METHODS}

Patients who had participated in the first part of the study were further assessed at approximately 30

From: Department of Ophthalmology, Kent and Canterbury Hospital, Canterbury, Kent CT1 3NG, UK.

Correspondence to: A. M. O'Driscoll, FRCOphth, Birmingham and Midland Eye Hospital, Church Street, Birmingham B3 2NS, UK. months following cataract surgery. They had all undergone an identical extracapsular technique with limbal incisions, but received either polypropylene or nylon suture. All patients were examined for wound complications. Only those included in the original astigmatism study were assessed for further changes in astigmatism.

\section{Clinical Assessment}

Best corrected Snellen visual acuity was recorded. Astigmatism and axes were measured with a HaagStreit Javal Schiotz keratometer by one observer. Full slit lamp biomicroscopy was performed on each patient. The presence of giant papillary conjunctivitis (GPC), protruding sutures, hydrolysed sutures, wound ectasis, conjunctival hyperaemia and posterior capsular opacification was to noted. Hydrolysis was clinically defined as thinning and loss of coloration of the suture material. Wound ectasis was defined as stretching of the surgical section in the direction parallel to the orientation of the sutures.

\section{Vector Analysis}

The data from all previous examinations were subjected to vector analysis and vector decomposition assessment to demonstrate the post-operative changes in induced astigmatism more clearly.

Data were analysed using Student's $t$-test and Fisher's exact test.

\section{RESULTS}

Follow-up

Of the original 44 patients whose astigmatism was analysed, 3 had died, 3 had not responded to the follow-up request, 2 were too confused to attend, 2 refused to attend on the basis of being too old, 1 had had a cerebrovascular accident and 1 had a central retinal vein occlusion. This left 32 patients for astigmatism analysis, 26 female and 6 male. The average age of the nylon group was 78.3 years 
Table I. Late post-operative complications according to suture type

\begin{tabular}{lcc}
\hline & Polypropylene & Nylon \\
\hline No. of patients & 17 & 19 \\
Wound ectasis & 2 & 1 \\
Conjunctival hyperaemia & $11^{*}$ & $4^{*}$ \\
Hydrolysed sutures & $0^{*}$ & $17^{*}$ \\
Knot exposed & 4 & 0 \\
Giant papillary conjunctivitis & 4 & 0 \\
Posterior capsule opacification & 5 & 8 \\
\hline
\end{tabular}

${ }^{*} p<0.02$ (Fisher's exact test).

( $\mathrm{SD} \pm 14.1)$ and of the polypropylene group 81.3 years $(\mathrm{SD} \pm 10.9)$.

\section{Complications and Exclusions}

The findings of the slit lamp examination are summarised in Table I. The surgical sections of the patients with wound ectasis were otherwise well healed. Hyperaemia of the conjunctiva in the polypropylene group was related to the unburied knot, whereas in the nylon group this was associated with hydrolysis. All the patients with GPC had exposed suture knots, though none was symptomatic. Apart from those with posterior capsular opacification, 3 patients from each group had previously had YAG laser posterior capsulotomies.

After the 3 month assessment, 1 patient from the nylon group had all her sutures removed because of intolerable astigmatism and 2 of the polypropylene group had all their sutures removed because of symptomatic GPC due to exposed knots. Their astigmatism results are shown in Fig. 2 but their data are not included in the analysis in Table II.

\section{Visual Acuity}

Fig. 1 shows the corrected visual acuities of both groups at 30 months. Since posterior capsular opacification had not yet been treated in all the patients, the results were not statistically analysed. The one patient with a visual acuity of $6 / 60 \mathrm{had}$ developed age-related macular degeneration.

\section{Vector Analysis}

The vector decomposition for each patient is presented in Fig. 2. The results of the average induced astigmatism are shown in Table II. The average vector decomposition for each group is shown in Fig. 3.

\section{DISCUSSION}

Vector analysis was used to analyse astigmatism in this study because both the induced astigmatism and the axis are taken into account. Vector decomposition complements the analysis by differentiating the with-the-rule from the against-the-rule component. ${ }^{2}$ This provides a simple but adequate representation of a complex alteration in corneal topography without having to resort to the use of more expensive equipment.

Both the study and the control group showed a marked increase in astigmatism towards 30 months post-operatively. Vector analysis has revealed greater values due to induced astigmatism as opposed to values from absolute astigmatism analysis previously noted in these patients. ${ }^{1}$ Vector decomposition has demonstrated a greater against-the-rule component in the polypropylene group than in the nylon group at 30 months, though there is no statistical difference in induced astigmatism between them.

The elastic polypropylene suture, despite being non-hydrolysable, has allowed a late shift in astigmatism. This may be due to an excessive ratio of wound-length to suture number, as well as to its marked elasticity. Hydrolysis of the nylon sutures during this period has similarly contributed to

\section{Elastic polypropylene $\square$ Nylon}

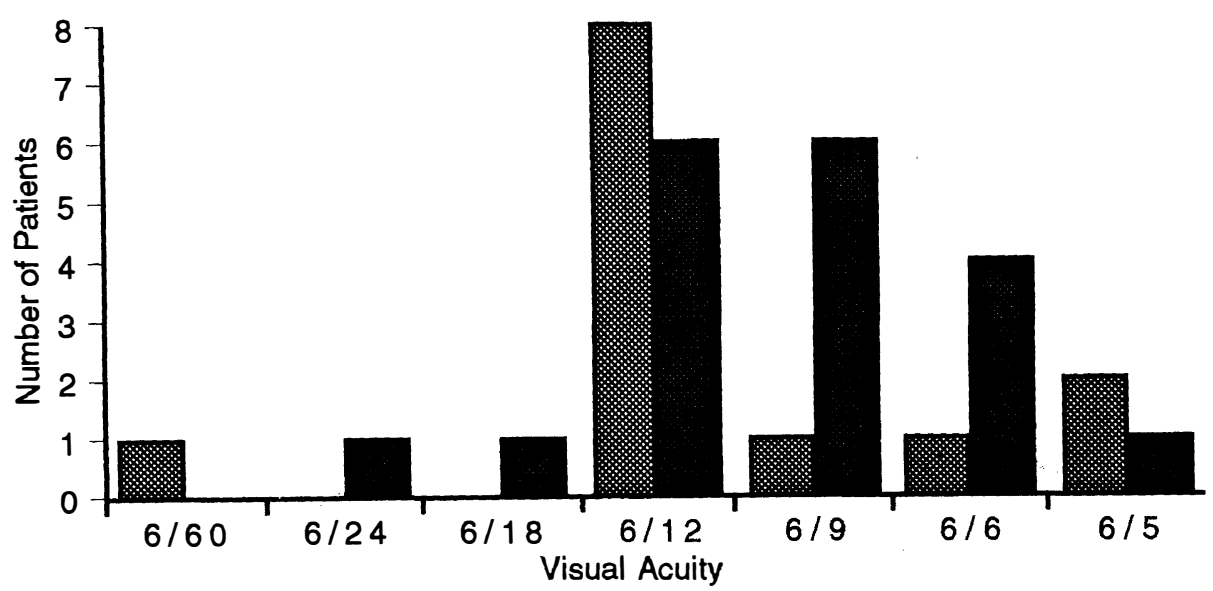

Fig. 1. The best corrected visual acuity in the polypropylene and nylon suture groups at 30 months. 


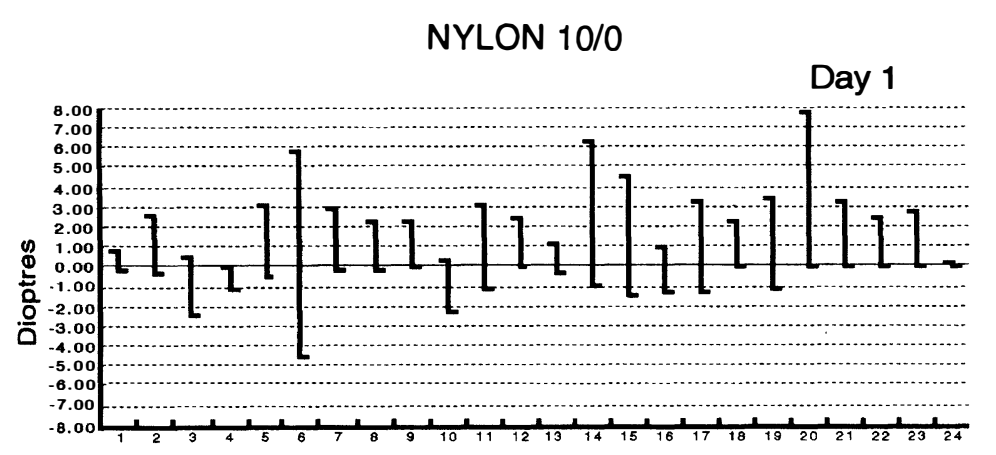

ELASTIC POLYPROPYLENE 9/0

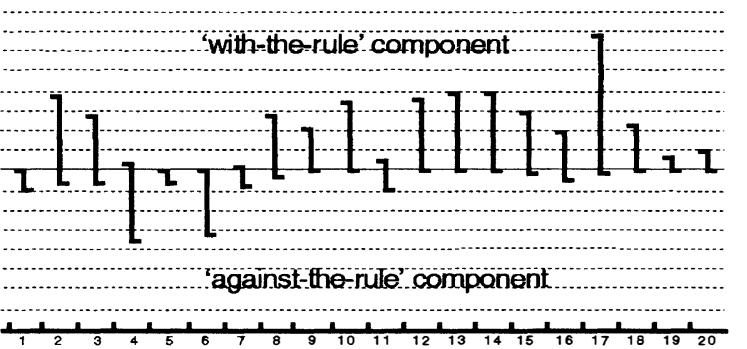

Week 1

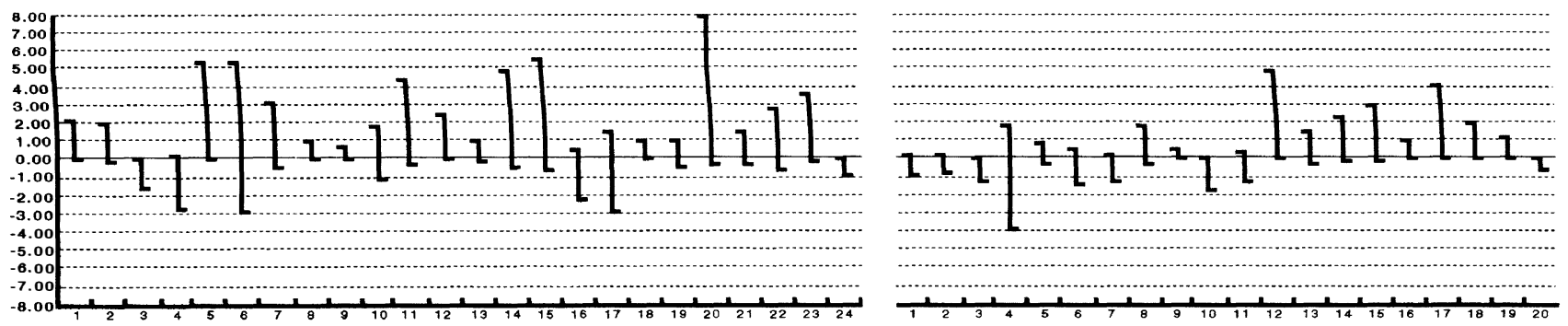

Month 1

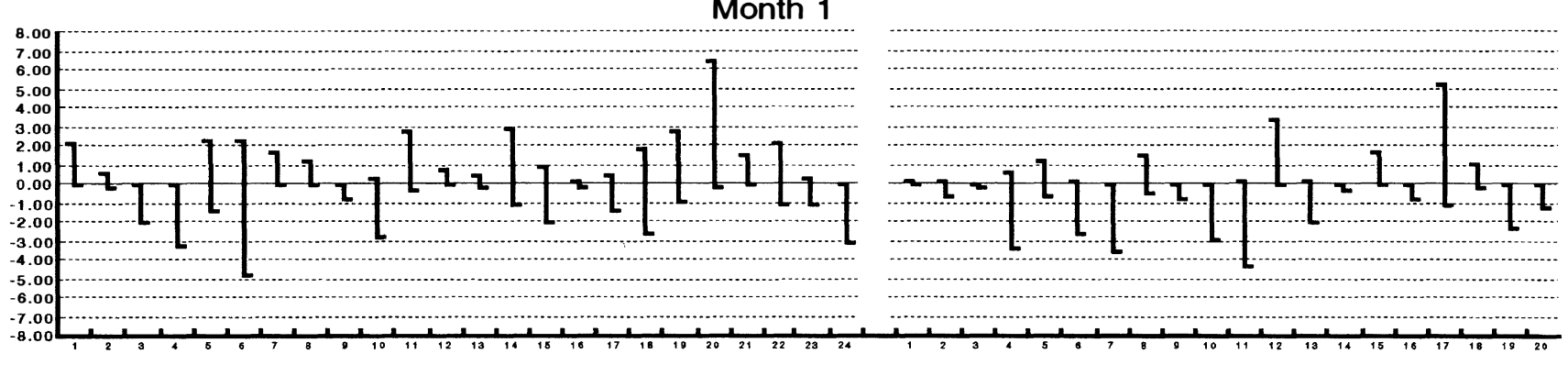

Month 3

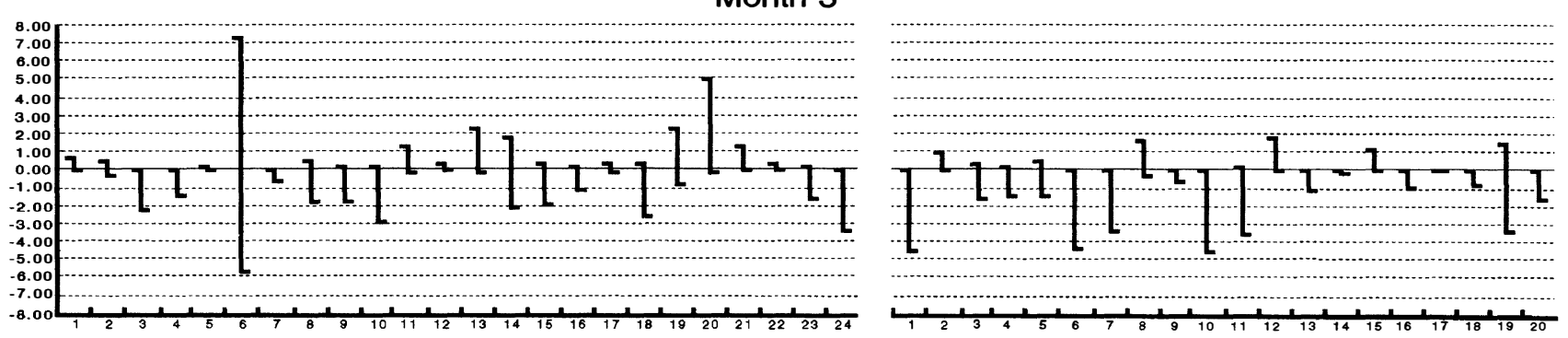

Month 30
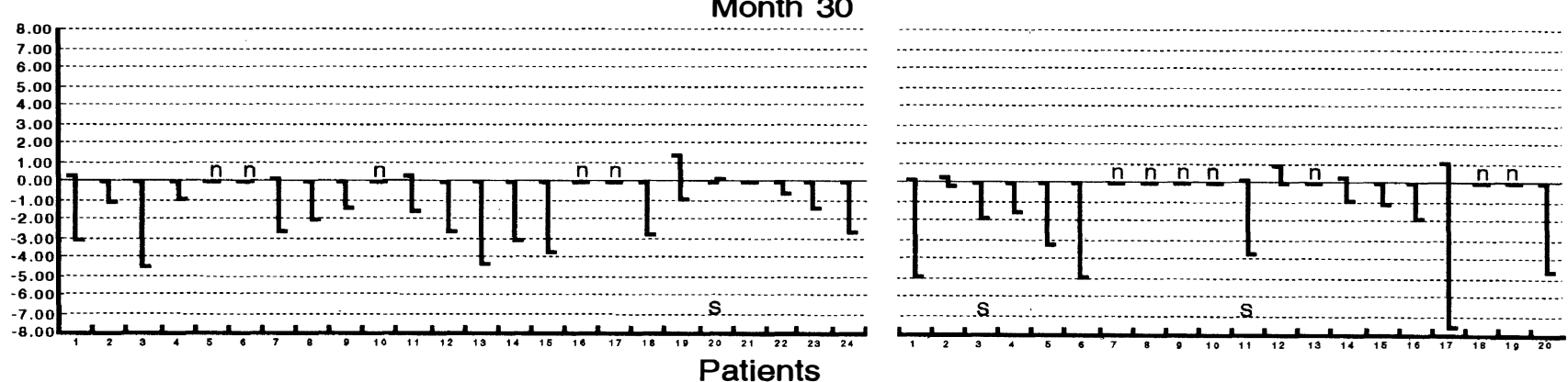

Fig. 2. Vector decomposition graphs illustrating the change in induced astigmatism for each patient over time. $n$, no data; $s$, all sutures removed by month 6 . 


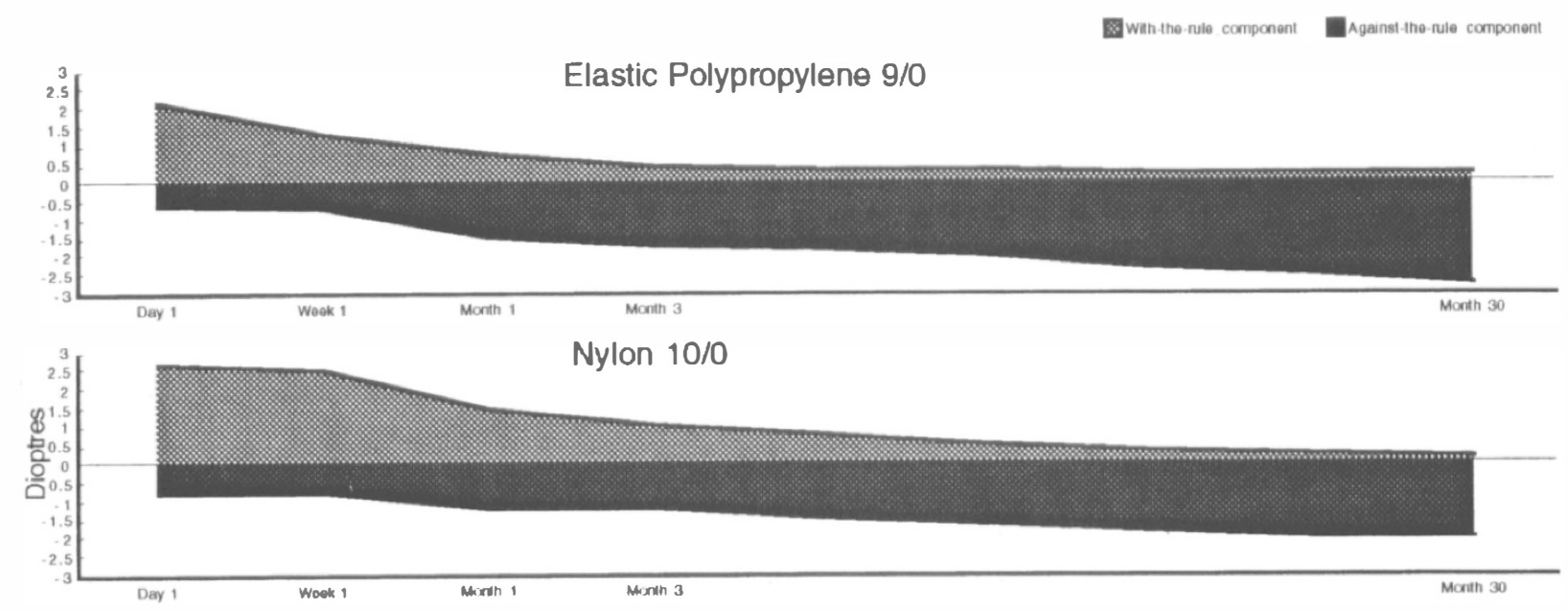

Fig. 3. The average change in induced astigmatism in the polypropylene and nylon suture groups by vector decomposition.

Table II. A comparison, by vector analysis, of the average induced astigmatism (in dioptres) in the polypropylene and nylon suture groups

\begin{tabular}{|c|c|c|c|c|c|}
\hline & \multicolumn{5}{|c|}{ Post-operative time } \\
\hline & 1 day & 1 week & 1 month & 3 months & 30 months \\
\hline Polypropylene & $2.8( \pm 1.6)$ & $2.0 *( \pm 1.4)$ & $2.3( \pm 1.6)$ & $2.1( \pm 1.6)$ & $3.0( \pm 2.3)$ \\
\hline Nylon & $3.5( \pm 2.3)$ & $3.3 *( \pm 2.2)$ & $2.7( \pm 1.8)$ & $2.3( \pm 2.2)$ & $2.3( \pm 1.3)$ \\
\hline
\end{tabular}

$* p<0.05(t$-test).

against-the-rule astigmatism. ${ }^{3}$ Continued drift towards against-the-rule astigmatism would appear to parallel that seen with other suture materials and surgical techniques. ${ }^{4,5}$ One might expect the elastic polypropylene suture, because of its greater thickness and therefore greater tensile strength, to have prevented this trend from occurring.

Despite the elasticity of the polypropylene suture possibly playing a role in poor wound security early on, ${ }^{1}$ there was no measurable difference in wound security between the two groups at 30 months. It appears that the polypropylene suture provides adequate apposition of the surgical section to aid healing.

Hydrolysis in the nylon suture in 17 (89\%) patients produced only asymptomatic conjunctival hyperaemia, probably because the surgical sections were placed at the limbus and the sutures were well covered by conjunctiva and Tenon's fascia. The polypropylene suture showed no evidence of hydrolysis. GPC was consistently associated with exposed, unburied polypropylene knots (24\%) and was therefore not directly due to the presence of polypropylene suture as such.

In conclusion, the $9 / 0$ elastic polypropylene suture (Opthamend) showed remarkable elastic properties by inducing less post-operative astigmatism initially, but it could not prevent against-the-rule astigmatism at 30 months post-operatively. It appears to be safe in the long term and more biocompatible than nylon suture since it did not hydrolyse.

A. M. O'Driscoll, M. M. Quraishy and N. Andrew have no proprietary interest in the Opthamend suture.

Key words: Elastic polypropylene suture, Induced astigmatism, Vector analysis.

\section{REFERENCES}

1. O'Driscoll AM, Goble RR, Hallack GN, Andrew NC. A prospective, controlled study of a $9 / 0$ elastic polypropylene suture for cataract surgery: refractive results and complications. Eye 1994;8:538-42.

2. Dam-Johansen M, Olsen T, Theodorsen F. The longterm course of the surgically-induced astigmatism after a scleral tunnel incision. Eur J Implant Refract Surg 1994; 6:337-43.

3. Cravey TV. Long-term corneal astigmatism related to selected elastic, monofilament, nonabsorbable sutures. J Cataract Refract Surg 1989;15:61-9.

4. Masket S. Comparison of suture materials for closure of the scleral pocket incision. J Cataract Refract Surg 1988;14:548-51.

5. Wishart MS, Wishart PK, Gregor ZJ. Corneal astigmatism following cataract extraction. $\mathrm{Br} \mathrm{J}$ Ophthalmol 1986;70:825-30. 